\title{
The Change of Range of Motion at Anterior Compression of the Cervical Cord after Laminoplasty in Patients with Cervical Spondylotic Myelopathy
}

\author{
Yongjae Cho \\ Department of Neurosurgery, Ewha Womans University School of Medicine, Seoul, Korea
}

\begin{abstract}
Objective: Degenerative diseases of the spine, such as cervical spondylotic myelopathy (CSM), are increasing among the old age population, and surgical treatment of CSM is becoming more and more common. The aim of this study was to investigate how functional recovery can be influenced by anterior compression of the spinal cord (ACS) after laminoplasty for treatment of patients with CSM.

Methods: We retrospectively analyzed 32 patients admitted to Ewha Womans Mok-Dong Hospital with CSM who underwent open-door laminoplasty from January 2012 to December 2014. We divided patients into 2 groups according to whether ACS was or not preoperatively. Each group was analyzed clinical and radiological parameters which were Japanese Orthopedic Association (JOA) scores and its recovery rate, sagittal alignment and range of motion (ROM).

Results: The mean duration of symptom was 11.2 months (range, 6-22 months). A significant difference in recovery rate of the total JOA score was shown between the 2 groups, especially upper extremity motor function. No difference in preoperative JOA score between the 2 groups, but recovery rate of each group was $20.05 \% \pm 18.1 \%, 32.21 \% \pm 25.4 \%$, statistically significant $(p<0.005)$. Upper motor and sensory function was not significantly different in the 2 groups. Preoperative, postoperative and preservation of ROM was $44.3^{\circ} \pm 10.1^{\circ}, 41.8^{\circ} \pm 15.7^{\circ}, 87.9 \% \pm 35.4 \%$ each at ACS (-) group. A significant difference in postoperative ROM was identified between ACS (-) and ACS (+) group. Postoperative anterior compression of the spinal cord was recognized 14 cases which were classified from its causes.

Conclusion: Cervical ROM decreased significantly after laminoplasty, but $85.3 \%$ of the preoperative ROM was preserved. The postoperative reduction of ROM in group with anterior compression of spinal cord was identified.
\end{abstract}

Key Words: Cervical Spondylosis $\cdot$ Myelopathy

\section{INTRODUCTION}

Cervical spondylotic myelopathy (CSM) is one of the most prevailing and increasingly observed spinal cord disorders in the geriatric population ${ }^{14)}$. Posterior approaches to decompress the cervical spine include laminectomy, laminoplasty, and laminectomy with fusion. Although cervical laminectomy used to have been widely employed in the treatment of progressive myelopathy, complications such as kyphotic deformity, segmental instability, postoperative adhesions, have been well recognized ${ }^{4}$. Cervical laminoplasty, a surgical alternative

- Received: August 24, 2016 • Revised: November 15, 2016

- Accepted: November 17, 2016

Corresponding Author: Yongjae Cho

Department of Neurosurgery, Ewha Womans University Mok-Dong

Hospital, Ewha Womans University School of Medicine, 1071

Anyangcheon-ro, Yangcheon-gu, Seoul 07985, Korea

Tel: +82-2-2650-2658, Fax: +82-2-2655-2652

E-mail: yongcho@ewha.ac.kr

$\circledast$ This is an open access article distributed under the terms of the Creative Commons Attribution Non-Commercial License (http://creativecommons.org/licenses/by-nc/4.0/) which permits unrestricted non-commercial use, distribution, and reproduction in any medium, provided the original work is properly cited. to laminectomy, has advantages such as lower incidence of postoperative cervical kyphosis and preservation of the range of motion (ROM) of the cervical spine ${ }^{2,4)}$. After laminoplasty, effective decompression is obtained when lordosis of the cervical spine is maintained to allow posterior migration of the spinal cord after laminoplasty ${ }^{2,4)}$. Therefore, the success rate of laminoplasty depends on the pre- and postoperative preservation of cervical spine lordosis ${ }^{2,24)}$.

Many authors observed patients who developed postoperative kyphosis, although preoperative lordosis had been maintained ${ }^{8,23}$. Several studies have reported a significantly decreased flexion and extension ROM after laminoplasty ${ }^{12,20)}$. A large number of patients and longer follow-up periods are necessary for a more detailed determination of decrease in ROM after cervical laminoplasty.

Some investigators claimed that the presence of anterior compression of the spinal cord (ACS) will prevent improvements in neurologic outcome and cause the patients to be considerable suffering ${ }^{4}$. We, therefore, retrospectively performed an analysis of radiological and clinical results to investigate how functional recovery can be influenced by ACS after laminoplasty for treatment of patients with CSM. 


\section{MATERIALS AND METHODS}

\section{Patients}

The retrospective study population comprised 32 patients with CSM who underwent open-door laminoplasty from January 2012 to December 2014. Inclusion criteria were following: patients with CSM who underwent more than 3 segment open-door laminoplasty in author's hospital from January 2012 to December 2014, all clinical and radiological data were available, more than 2-year follow-up period. Exclusion criteria were the following: (1) ossification of the posterior longitudinal ligament; (2) history of rheumatoid arthritis, cerebral palsy, or tumors; (3) single-level cervical disc herniation; (4) destructive spondyloarthropathy due to medical disease such as chronic renal or hepatic disease; (5) previous cervical surgery. All of these 32 patients were observed for more than 24 months after surgery in this study with a mean age of 64.2 years (range, 56-78 years) and mean disease duration of 10.3 months (range, 6-21 months). All patients presented with symptoms of myelopathy confirmed by a physical examination. Magnetic resonance imaging as well as computed tomography scan findings were consistent with myelopathy secondary to multisegmental cervical spondylotic stenosis. The Institutional Review Board of Ewha Womans Mok-Dong Hos-
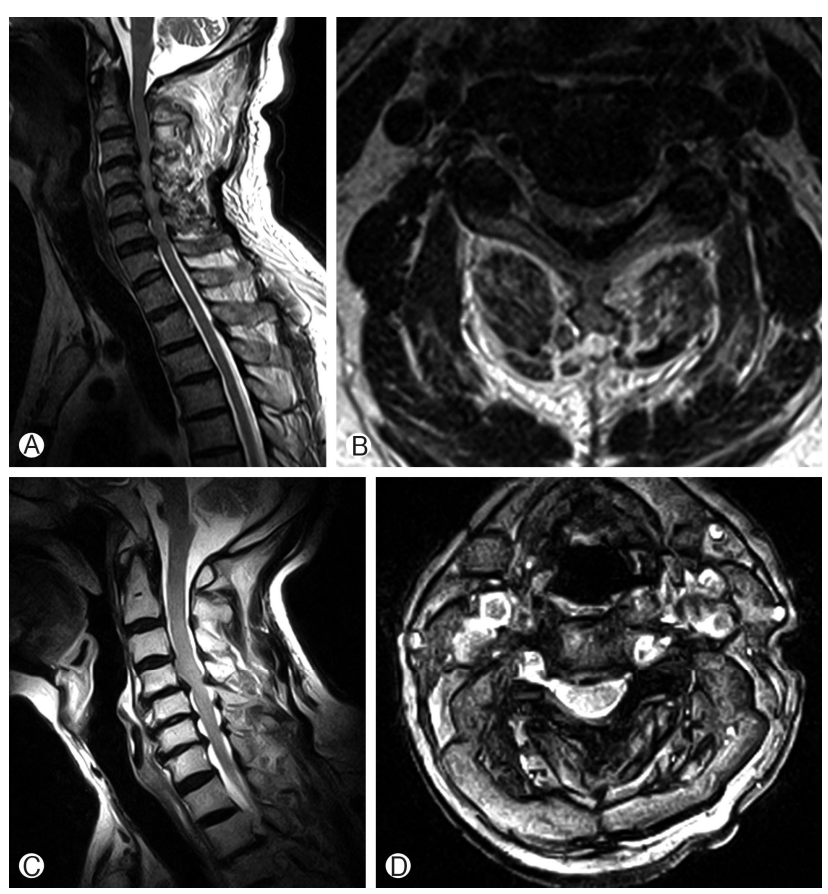

Fig. 1. Magnetic resonance imaging shows anterior compression of spinal cord. Effacement of anterior cerebral spinal fluid buffer on the T2 sagittal (A) and axial (B) images was considered as anterior compression of the spinal cord. Panels (C) and (D) shows case without effacement of anterior cerebral spinal fluid buffer on the T2. pital approved this study.

All 32 patients underwent open-door laminoplasty by splitting of the one side lamina-facet line using a high-speed drill to elevate and decompress cervical cord. In these cases, surgical exposure was limited as much as possible and the muscles attached to the $\mathrm{C} 2$ spinous process were preserved without detachment. At the other side, gutters were created as hinges at the border between the laminae and facets.

After surgery, all patients were allowed to sit up and walk on the second postoperative day while wearing a Philadelphia collar. The collars were applied in all patients for the 4 weeks. Cervical ROM exercises were performed 7 days after operation according to the rehabilitation program. Regular outpatient clinic visit was done.

We divided patients into the 2 groups according to whether ACS was or not preoperatively (Figs. 1, 2). ACS (+) was 20 cases and another group 12 cases. Each group was analyzed
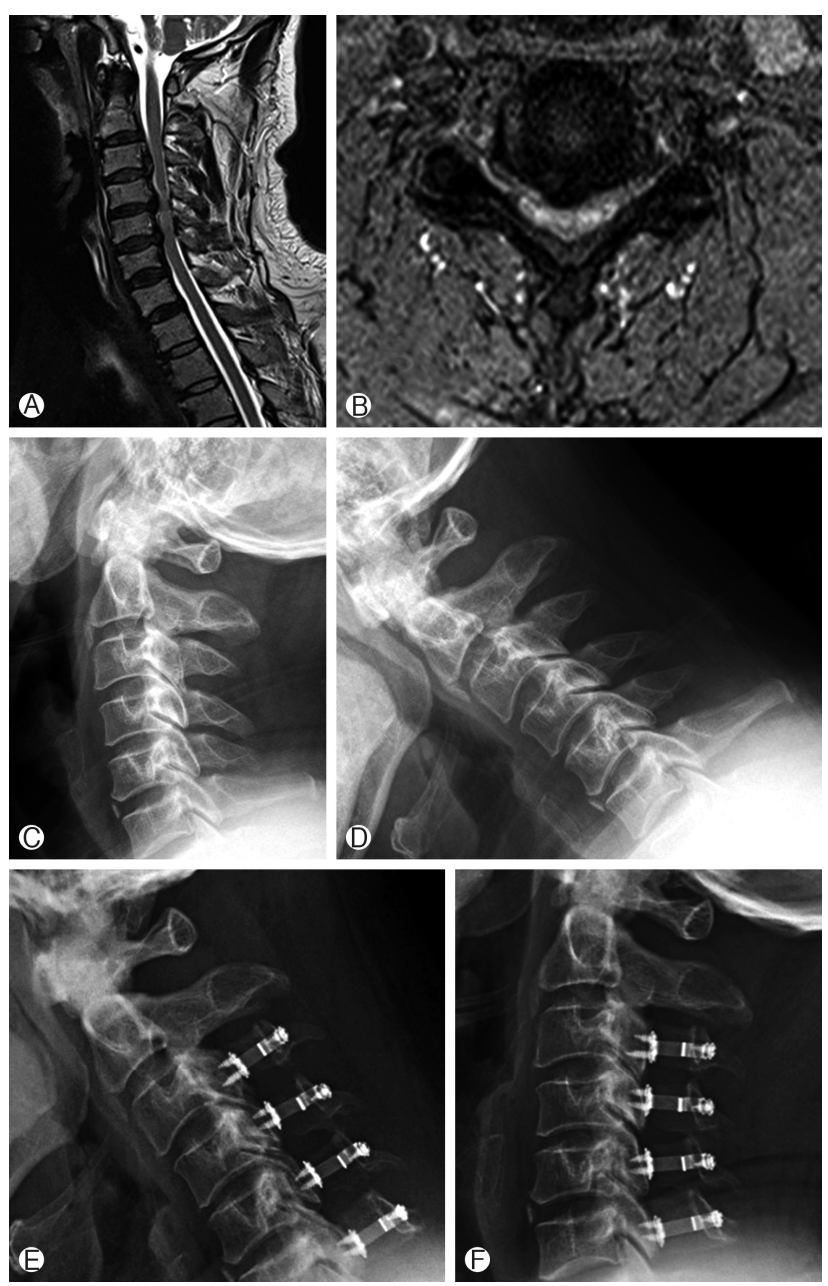

Fig. 2. This patient's case shows that the postoperative reduction of range of motion (ROM) in group with anterior compression of spinal cord was identified. (A, B) Anterior compression of the spinal cord. (C, D) The preoperative ROM of cervical spine. (E, F) The postoperative ROM of cervical spine. 
following parameters.

\section{Clinical Outcome}

Japanese Orthopedic Association (JOA) scoring system was used for the evaluation of neurologic and clinical status of patients preoperatively and postoperatively. JOA scoring system, which consists of 7 categories including upper extremity motor function, lower extremity motor function, sensation of upper or lower extremity and trunk was used to evaluate cervical myelopathy before, after surgery, and to last followup $^{21)}$. Recovery rate (RR) was calculated using the method of Hirabayashi ${ }^{17}$ method to compare pre- and postoperative JOA scores; (postoperative JOA score-preoperative JOA score) $\times$ 100/(17- preoperative JOA score).

\section{Radiological Analysis}

The lordotic angle between $\mathrm{C} 2$ and $\mathrm{C} 7$ was measured before surgery and at the final follow-up in the neutral and maximal flexion-extension lateral radiographical view by the Cobb method, with negative and positive lordotic angles indicating cervical kyphosis and lordosis, respectively ${ }^{19}$. Changes

Table 1. Demographic data of patients

\begin{tabular}{|c|c|c|c|}
\hline Variable & $\begin{array}{c}\operatorname{ACS}(+) \\
\text { group }(n=20)\end{array}$ & $\begin{array}{c}\operatorname{ACS}(-) \\
\text { group }(n=12)\end{array}$ & p-value \\
\hline Age (yr) & $65.1 \pm 11.6$ & $63.2 \pm 10.2$ & NS \\
\hline Ratio (male:female) & $2.47: 1$ & $2.65: 1$ & NS \\
\hline Duration of symptom (mo) & $10.8 \pm 4.5$ & $11.5 \pm 10.3$ & NS \\
\hline \multicolumn{4}{|l|}{ Segment of stenosis (cases) } \\
\hline $\mathrm{C} 3-5$ & 5 & 1 & \\
\hline $\mathrm{C} 3-6$ & 8 & 8 & \\
\hline $\mathrm{C} 3-7$ & - & 2 & \\
\hline C4-6 & 4 & - & \\
\hline C4-7 & 3 & 1 & \\
\hline \multicolumn{4}{|l|}{ Level of ACS } \\
\hline $\mathrm{C} 4 / 5$ & 6 & - & \\
\hline $\mathrm{C} 5 / 6$ & 4 & - & \\
\hline $\mathrm{C} 4 / 5 / 6$ & 6 & - & \\
\hline $\mathrm{C} 6 / 7$ & 1 & - & \\
\hline $\mathrm{C} 5 / 6 / 7$ & 3 & - & \\
\hline \multicolumn{4}{|l|}{ Extent of laminoplasty } \\
\hline $\mathrm{C} 3-5$ & 3 & 3 & \\
\hline $\mathrm{C} 3-6$ & 8 & 4 & \\
\hline $\mathrm{C} 3-7$ & 4 & 0 & \\
\hline $\mathrm{C} 4-6$ & 2 & 2 & \\
\hline $\mathrm{C} 4-7$ & 1 & 1 & \\
\hline
\end{tabular}

Values are presented as mean \pm standard deviation or number of cases.

ACS, anterior compression of the spinal cord; NS, not significant. in the alignment of the cervical spine were assessed in the following manner: Alignment change $\left(^{\circ}\right)=($ preoperative $\mathrm{C} 2-\mathrm{C} 7$ lordotic angle)-(postoperative $\mathrm{C} 2-\mathrm{C} 7$ lordotic angle), The ROM in flexion-extension: ROM change $\left(^{\circ}\right)=($ preoperative ROM) - (postoperative ROM).

As described by Hiraizumi ${ }^{7}$ in 2008, Effacement of anterior cerebral spinal fluid buffer on the T2 sagittal and axial images and evidence of anterior compression of cord on the T1 sag and axial images was considered as ACS.

\section{Range of Motion}

ROM of the cervical spine was assessed by measuring the difference in alignment at flexion and extension ${ }^{15}$. Total ROM value was obtained by summation of these angles. The changes in ROM and preservation rates were evaluated in the following manner: ROM change $\left({ }^{\circ}\right)=$ (preoperative ROM) - (postoperative ROM), Proportion of ROM preserved (ROM preservation, $\%)=($ postoperative $\mathrm{ROM}) /($ preoperative $\mathrm{ROM}) \times 100$.

\section{Statistical Analysis}

A Statistical software package (SPSS ver. 12, SPSS Inc., Chicago, IL, USA) was used for statistical analysis. All values are expressed as means \pm standard deviation. The paired $\mathrm{t}$-test was used for analyzing the differences between the 2 groups. A p-value of less than 0.05 was considered statistically significant.

\section{RESULTS}

There was no significant difference in demographic data between the 2 groups (Table 1). ACS was likely to be seen at $\mathrm{C} 4 / \mathrm{C} 5$ or $\mathrm{C} 5 / \mathrm{C} 6$ (mainly $\mathrm{C} 5$ above and below) ${ }^{6}$. In this study, ACS (20 cases) was identified C4/5 (6 cases), C5/6 (4 cases), C4/5/6 (6 cases), C6/7 ( 1 case), and C5/6/7 (3 cases). Extent of laminoplasty was C3-5 (3 cases), C3-6 (8 cases), C3-7 (4 cases), C4-6 (2 cases), and C4-7 (3 cases) in ACS $(+)$ group. In patients group without ACS, C3-5 (3 cases), C3-6 (4 cases), C4-6 (2 cases), and C4-7 (1 case). The extent of laminoplasty level was shown in Table 1 . It show that $\mathrm{C} 3-5$ (3 cases), C3-6 (8 cases), C3-7 (4 cases), C4-6 (2 cases), C4-7 (3 cases) in ACS (+) group and C3-5 (3 cases), C3-6 (4 cases), C4-6 (2 cases), C4-7 (1 cases) in ACS (-) group.

A significant difference in RR of the total JOA score was shown between the 2 groups, especially upper extremity motor function (Table 2). No difference in preoperative JOA score between the 2 group, but RR of each group was 20.05\% $\pm 18.1 \%, 32.21 \% \pm 25.4 \%$, statistically significant $(\mathrm{p}<0.005)$. Upper motor and sensory function was not significantly different in 2 group.

No significant difference between the groups in kyphotic change and preoperative ROM was observed (Fig. 2). The mean alignment in ACS $(+)$ group was $11.9^{\circ} \pm 10.3^{\circ}$ preoperatively 
and $10.6^{\circ} \pm 12.3^{\circ}$ postoperatively. At ACS (-) group, the kyphotic angle was $13.4^{\circ} \pm 9.9^{\circ}$ preoperatively and $11.1^{\circ} \pm 10.67^{\circ}$ postoperatively. Angle change through laminoplasty were $1.8^{\circ}$ $\pm 8.9^{\circ}$ at $\mathrm{ACS}(+)$ and $2.1^{\circ} \pm 9.7^{\circ}$ at $\mathrm{ACS}(-)$. In ACS (+) group, ROM of cervical spine was $40.1^{\circ} \pm 11.7^{\circ}$ and $33.5^{\circ} \pm 12.0^{\circ}$ preoperatively and postoperatively, $71.2 \% \pm 38.0 \%$ preservation of ROM. Preoperative, postoperative and preservation of $\mathrm{ROM}$ was $44.3^{\circ} \pm 10.1^{\circ}, 41.8^{\circ} \pm 15.7^{\circ}, 87.9 \% \pm 35.4 \%$ each at ACS (-) group (Table 3).

A significant difference in postoperative ROM was identified between ACS (-) and ACS (+) groups.

Postoperative ACS was recognized 14 cases which were classified from its causes. The causes of postoperative ACS (+) was residual 4 cases and newly developed 2 cases. Residual cases were due to kyphosis, spondylolisthesis, and degenerative disc. Kyphosis was main cause in newly developed ACS cases (Table 4).

\section{DISCUSSION}

Degenerative diseases of the spine, such as CSM, are increasing among the old age population, and surgical treatment

Table 2. Clinical outcomes according to JOA score

\begin{tabular}{lccc}
\hline Variable & ACS (+) & ACS (-) & p-value \\
\hline Preoperative & $9.1 \pm 4.8$ & $12.0 \pm 3.3$ & NS \\
Postoperative & $12.1 \pm 2.2$ & $13.8 \pm 2.4$ & $<0.05$ \\
RR of JOA score (\%) & $20.05 \pm 18.1$ & $32.21 \pm 25.4$ & $<0.05$ \\
Motor function & & & \\
$\quad$ Upper extremity & $33.9 \pm 20.5$ & $69.4 \pm 22.5$ & $<0.05$ \\
$\quad$ Lower extremity & $42.5 \pm 20.6$ & $48.6 \pm 33.8$ & NS \\
Sensory function & & & \\
$\quad$ Upper extremity & $55.3 \pm 18.6$ & $40.1 \pm 40.5$ & NS \\
$\quad$ Lower extremity & $65.3 \pm 40.5$ & $80.6 \pm 41.5$ & NS \\
\hline
\end{tabular}

Values are presented as mean \pm standard deviation

JOA, Japanese Orthopedic Association; ACS, anterior compression of the spinal cord; RR, recovery rate; NS, not significant.

Table 3. Radiologic outcomes

\begin{tabular}{lccc}
\hline \hline Variable & ACS $(+)$ & ACS $(-)$ & p-value \\
\hline Kyphotic angle $\left(^{\circ}\right)$ & & & \\
Preoperative & $11.9 \pm 10.3$ & $13.4 \pm 9.9$ & NS \\
Postoperative & $10.6 \pm 12.3$ & $11.1 \pm 10.67$ & NS \\
Angle change & $1.8 \pm 8.9$ & $2.1 \pm 9.7$ & NS \\
ROM $\left(^{\circ}\right)$ & & & \\
Preoperative & $40.1 \pm 11.7$ & $44.3 \pm 10.1$ & NS \\
Postoperative & $33.5 \pm 12.0$ & $41.8 \pm 15.7$ & $<0.05$ \\
Preservation $(\%)$ & $71.2 \pm 38.0$ & $87.9 \pm 35.4$ & $<0.05$ \\
\hline
\end{tabular}

Values are presented as mean \pm standard deviation ACS, anterior compression of the spinal cord; ROM, range of motion; NS, not significant. of CSM is becoming more and more common ${ }^{14)}$. A number of laminoplasty procedures have been developed for the treatment of CSM. Many studies have shown that the surgical outcome of laminoplasty are satisfactory ${ }^{1,3,11,15,18,22,25)}$. However, postoperative complications may arise, including decreased cervical ROM and loss of cervical lordotic alignment, all of which may significantly impair the quality of life ${ }^{4,5,10)}$.

In this study, we conducted an analysis of radiographical and clinical data of 32 patients with CSM who underwent a single procedure at a single institution. Our findings suggest that patients' original preoperative cervical alignment was preserved in most cases, and the ROM preservation rate was $85.3 \%$ after laminoplasty (Table 3). These outcomes were same to other studies ${ }^{13)}$. Cervical laminoplasty as an alternative procedure for the treatment of multilevel cervical spondylosis, has some advantages compared with laminectomy or multilevel corpectomy. The purported advantage of cervical laminoplasty includes the ability to maintain segmental motion without sacrificing stability ${ }^{8,13,20,23)}$. However, there have been several reports describing a reduction in ROM and cervical malalignment after cervical laminoplasty such as kyphosis and spondylolisthesis, and these problems remain under discussion $^{24,13,24)}$. In many researches, ROM reduction is reported to range from $30 \%$ to $70 \%$ of the preoperative $\mathrm{ROM}^{17,22)}$.

In the present study, several modifications have been introduced to reduce the incidence of such postoperative problems after laminoplasty, ${ }^{4,11,12,15,18,24)}$. Some authors have reported a relationship between cervical ROM and cervical posterior muscle condition, especially that of the deep muscles, after laminoplasty ${ }^{3)}$. Another hypothesized cause of the reduction is spontaneous laminar fusion, for which several preventative methods have been considered ${ }^{22}$. Early mobilization after surgery has been recommended ${ }^{10)}$. These authors claimed that early removal of the cervical collar prevents contraction of the facet joint and postoperative atrophy and dysfunction of the extensor musculature of the cervical spine ${ }^{19)}$.

In the current study, we compared 2 groups, 1 group with anterior compression of spinal cord and the other without, to assess the incidence of developing kyphosis after laminoplasty. This finding led us to the conclusion that the tendency

Table 4. Analysis of postoperative ACS in 6 patients

\begin{tabular}{lcc}
\hline \hline Cause & $\begin{array}{c}\text { Residual } \\
\text { ACS } \\
(\mathrm{n}=4)\end{array}$ & $\begin{array}{c}\text { Newly } \\
\text { developed ACS } \\
(\mathrm{n}=2)\end{array}$ \\
\hline Kyphosis & $4^{*}$ & 2 \\
Spondylolisthesis & 1 & 0 \\
Disc & 2 & 1 \\
RR of JOA score (0) & $34.6+11.1$ & $45.1+13.6^{*}$
\end{tabular}

ACS, anterior compression of the spinal cord; RR, recovery rate; JOA, Japanese Orthopedic Association; SD, standard deviation.

"There are some overlapping cases in which two case have both kyphosis and Spondylolisthesis. 
of postlaminoplasty kyphosis is higher in the group with anterior compression of spinal cord. Certainly, postoperative kyphosis developed in the patients with preoperative kyphosis. Through the review the previous literature concerning ROM after cervical laminoplasty, preservation of postoperative cervical ROM is important to prevent adjacent segment disease that often accompanies anterior or posterior the sagittal lordotic alignment ${ }^{24)}$.

In 2003, Ratliff and Cooper ${ }^{16)}$ analyzed previous studies on various laminoplasties, and meta-analyzed more than 2,000 patients. They reported that after laminoplasty, ROM of the cervical spine decreased approximately 50\% (range, 20\%$70 \%$ ) compared with the preoperative $\mathrm{ROM}^{16}$. Many studies have described a decreased ROM of the cervical spine after laminoplasty, but the degree of decrease varied among authors ${ }^{9,20)}$. Many studies have described a decreased ROM of the cervical spine after laminoplasty, but the degree of decrease varied among authors ${ }^{13,23)}$.

The decompression effect of laminoplasty has been claimed due to an indirect anterior decompression effect by posterior shift of the spinal cord from the anterior compressive lesion as well as a direct posterior decompression ${ }^{6}$. Restoration of the anterior subarachnoid space could be a significant factor for neurologic improvement after posterior decompression surgery $^{7}$. Posterior shift of the spinal cord of more than 3-mm leads to good recovery of myelopathy symptoms, but little shift by restraining dentate ligaments and nerve roots may occur limited recovery ${ }^{7}$.

In our study, a significant difference in postoperative ROM was identified between ACS (-) and ACS (+) groups. The postoperative reduction of ROM in group with anterior compression of spinal cord was identified. It was hypothesized that anterior compression of spinal cord may contribute to decrease of neck motion than no anterior compression of spinal cord group.

This study had several limitations. One limitation of this study involves our method of estimating cervical ROM. therefore, cervical movement is multidirectional, but in our study, radiological analysis of movement in only 1 plane was measured. Multidirectional movements, including rotational motion and lateral bending were not considered. In addition, any effect of reduced ROM on restriction of activity, or on daily life, was not evaluated. The follow-up period was not very long as well as small number of patients. Surgical level was heterogeneous, which consisted of 3-, 4-, 5-level laminoplasty. So, it could affect the range of motion. A critical limitation of this study was the lack of a comparative group of patients who underwent the other procedure. Therefore, we could not compare the radiographical outcomes between patients with CSM who underwent other surgical laminoplasty methods.

\section{CONCLUSION}

Cervical ROM decreased significantly after laminoplasty, but $85.3 \%$ of the preoperative ROM was preserved. The postoperative reduction of ROM in group with anterior compression of spinal cord was identified. So, surgeons consider preoperatively this point.

\section{CONFLICT OF INTEREST}

No potential conflict of interest relevant to this article was reported.

\section{REFERENCES}

1. Arantes Júnior AA, Silva Junior GA, Malheiros JA, Gonçalves FF, Magaldi M, Santiago E, et al: A new expansive two-opendoors laminoplasty for multilevel cervical spondylotic myelopathy: technical report and follow-up results. Arq Neuropsi-quiatr 72:49-54, 2014

2. Baba H, Maezawa Y, Furusawa N, Imura S, Tomita K: Flexibility and alignment of the cervical spine after laminoplasty for spondylotic myelopathy. A radiographic study. Int Orthop 19:116121, 1995

3. Charles YP, Schuller S, Sfeir G, Steib JP: French door laminoplasty for cervical spondylotic myelopathy. Eur Spine J 22:21232125, 2013

4. Denaro V, Longo UG, Berton A, Salvatore G, Denaro L: Cervical spondylotic myelopathy: the relevance of the spinal cord back shift after posterior multilevel decompression. A systematic review. Eur Spine J 24 Suppl 7:832-841, 2015

5. Fei Q, Li J, Su N, Wang B, Li D, Meng H, et al: Comparison between anterior cervical discectomy with fusion and anterior cervical corpectomy with fusion for the treatment of cervical spondylotic myelopathy: a meta-analysis. Ther Clin Risk Manag 11:1707-1718, 2015

6. Hirai T, Kawabata S, Enomoto M, Kato T, Tomizawa S, Sakai $\mathrm{K}$, et al: Presence of anterior compression of the spinal cord after laminoplasty inhibits upper extremity motor recovery in patients with cervical spondylotic myelopathy. Spine (Phila Pa 1976)37: 377-384, 2012

7. Hiraizumi Y: Spinal cord anterior decompression for delayed spinal cord paralysis after osteoporotic vertebral compression fracture: application of thoracoscopic approach. Chir Narzadow Ruchu Ortop Pol 73:67-73, 2008

8. Kaplan L, Bronstein Y, Barzilay Y, Hasharoni A, Finkelstein J: Canal expansive laminoplasty in the management of cervical spondylotic myelopathy. Isr Med Assoc J 8:548-552, 2006

9. Kimura I, Shingu H, Nasu Y: Long-term follow-up of cervical spondylotic myelopathy treated by canal-expansive laminoplasty. J Bone Joint Surg Br 77:956-961, 1995

10. Laiginhas AR, Silva PA, Pereira P, Vaz R: Long-term clinical and radiological follow-up after laminectomy for cervical spondylotic myelopathy. Surg Neurol Int 6:162, 2015

11. Machino M, Yukawa Y, Hida T, Ito K, Nakashima H, Kanbara $\mathrm{S}$, et al: Modified double-door laminoplasty in managing multilevel cervical spondylotic myelopathy: surgical outcome in 520 patients and technique description. J Spinal Disord Tech 26:135140, 2013 
12. Martin-Benlloch JA, Maruenda-Paulino JI, Barra-Pla A, LaguiaGarzaran M: Expansive laminoplasty as a method for managing cervical multilevel spondylotic myelopathy. Spine (Phila Pa 1976) 28:680-684, 2003

13. Nayeb Aghaei H, Azimi P, Shahzadi S, Azhari S, Mohammadi $\mathrm{HR}$, Alizadeh P, et al: Outcome measures of functionality, social interaction, and pain in patients with cervical spondylotic myelopathy: a validation study for the iranian version of the copenhagen neck functional disability scale. Asian Spine J 9:901-908, 2015

14. Nouri A, Tetreault L, Singh A, Karadimas SK, Fehlings MG: Degenerative cervical myelopathy: epidemiology, genetics, and pathogenesis. Spine (Phila Pa 1976) 40:E675-693, 2015

15. Park HG, Zhang HY, Lee SH: Box-shape cervical expansive laminoplasty: clinical and radiological outcomes. Korean J Spine 11:152-156, 2014

16. Ratliff JK, Cooper PR: Cervical laminoplasty: a critical review. J Neurosurg 98(3 Suppl):230-238, 2003

17. Satomi K, Ogawa J, Ishii Y, Hirabayashi K: Short-term complications and long-term results of expansive open-door laminoplasty for cervical stenotic myelopathy. Spine J 1:26-30, 2001

18. Sheen JJ, Jeon SR: Midline splitting cervical laminoplasty using allogeneic bone spacers: comparison of fusion rates between cervical spondylotic myelopathy and ossification of posterior longitudinal ligament. Korean J Neurotrauma 10:60-65, 2014

19. Shufflebarger HL, King WF: Composite measurement of scolio- sis: a new method of analysis of the deformity. Spine (Phila Pa 1976) 12:228-232, 1987

20. Suda K, Abumi K, Ito M, Shono Y, Kaneda K, Fujiya M: Local kyphosis reduces surgical outcomes of expansive open-door laminoplasty for cervical spondylotic myelopathy. Spine (Phila Pa 1976) 28:1258-1262, 2003

21. Tetreault L, Kopjar B, Nouri A, Arnold P, Barbagallo G, Bartels $\mathrm{R}$, et al: The modified Japanese Orthopaedic Association scale: establishing criteria for mild, moderate and severe impairment in patients with degenerative cervical myelopathy. Eur Spine $\mathrm{J}$ [Epub ahead of print], 2016

22. Umeda M, Sasai K, Kushida T, Wakabayashi E, Maruyama T, Ikeura A, et al: A less-invasive cervical laminoplasty for spondylotic myelopathy that preserves the semispinalis cervicis muscles and nuchal ligament. J Neurosurg Spine 18:545-552, 2013

23. Wang MY, Shah S, Green BA: Clinical outcomes following cervical laminoplasty for 204 patients with cervical spondylotic myelopathy. Surg Neurol 62:487-492, 2004

24. Yonenobu K, Hosono N, Iwasaki M, Asano M, Ono K: Laminoplasty versus subtotal corpectomy. A comparative study of results in multisegmental cervical spondylotic myelopathy. Spine (Phila Pa 1976) 17:1281-1284, 1992

25. Yuan W, Zhu Y, Liu X, Zhou X, Cui C: Laminoplasty versus skip laminectomy for the treatment of multilevel cervical spondylotic myelopathy: a systematic review. Arch Orthop Trauma Surg 134:1-7, 2014 